\title{
ОЦЕНКА ЭНЕРГЕТИЧЕСКИХ СПЕКТРОВ ОТРАЖЕНИЙ В ИМПУЛЬСНЫХ ДОПЛЕРОВСКИХ МЕТЕОРАДИОЛОКАТОРАХ. Ч. 2. ПРЕДЕЛЬНЫЕ ВОЗМОЖНОСТИ
}

\author{
ЛЕХОВИЦКИЙ Д. И. ${ }^{1}$, АТАМАНСКИЙ Д. В. ${ }^{2}$, РАЧКОВ Д. С. ${ }^{1}$, СЕМЕНЯКА А. В. ${ }^{1}$ \\ ${ }^{1}$ Харьковский нацииональный университет радиоэлектроники, \\ Украина, Харьков, 61166, пр-т Ленина, 14 \\ ${ }^{2}$ Харьковский университет Воздушных Сил имени Ивана Кожедуба, \\ Украина, Харьков, 61023, ул. Сумская 77/79
}

\begin{abstract}
Аннотация. Проанализированы «предельные» возможности воспроизведения непрерывных энергетических спектров, в частности, спектров междупериодных флуктуаций отражений от метеообразований в импульсных доплеровских метеорадиолокаторах, в гипотетических условиях знания КМ анализируемых процессов. Обсуждаются причины известных недостатков классических (непараметрических) методов спектрального оценивания (СО) при воспроизведении формы спектров, рассмотрены известный и предлагаемый критерий, по которым количественно сравниваются предельные возможности воспроизведения спектров классическими и параметрическими «сверхразрешающими» методами СО. Показано, что «предельные» возможности методов СО несут важную, но не исчерпывающую информацию, на основе которой они должны выбираться для практического использования в реальных условиях априорной неизвестности статистических характеристик входных воздействий.
\end{abstract}

Ключевые слова: непрерывный энергетический спектр случайных процессов; спектральная функция; методы спектрального оценивания; авторегрессионная модель; метеообразование; доплеровский метеорадиолокатор; обеляющий фильтр

\section{ВВЕДЕНИЕ И ПОСТАНОВКА ЗАДАЧИ}

Статья посвящена количественной оценке «предельных» возможностей различных алгоритмов воспроизведения непрерывных энергетических спектров гауссовых случайных процессов, заданных $M$-мерными векторами их дискретных отсчетов.

Предельность понимается в том смысле, что реально априори неизвестные $M \times M \mathrm{KM}$ этих векторов полагаются заданными. Тем самым фактически исследуется зависимость точности воспроизведения спектров различными методами от размерности $M$ доступного вектора отсчетов анализируемого процесса.

Аналогично [1], в роли этого вектора выступает аддитивная смесь гауссового белого шума и стационарного процесса авторегрессии $(\mathrm{AP}-p)$ различного порядка $p$ [2]. Полагается для конкретности, что эти процессы моделируют отражения от метеообразований (МО) в импульсных доплеровских метеорадиолокаторах (ДМРЛ), а анализируемый вектор образован отсчетами их комплексных амплитуд в $M$ смежных интервалах зондирования из каждого элемента разрешения по дальности. Полученные при этом результаты справедливы для дискретных АР-процессов другой природы.

Статья существенно опирается на теорию, развитую в [1]. В ней применяются те же обозначения и аббревиатуры, которые для экономии места повторно не раскрываются. Перед номерами цитируемых из [1] формул, рисун- 


\section{БИБЛИОГРАФИЧЕСКИЙ СПИСОК}

1. Оценка энергетических спектров отражений в импульсных доплеровских метеорадиолокаторах. Ч. 1. Разновидности алгоритмов спектрального оцени- вания / Д. И. Леховицкий, Д. В. Атаманский, Д. С. Рачков, А. В. Семеняка // Радиоэлектроника. - 2015. - Т. 58, № 12. - С. 3-23. - (Известия вузов). - DOI : $\underline{10.20535 / \mathrm{S} 0021347015120018 .}$.

2. Дженкинс Г., Ваттс Д. Спектральный анализ и его приложения. - М.: Мир, 1971.—316 с.

3. О методах оценивания спектров случайных процессов / Д. И. Леховицкий, Д. С. Рачков, А. В. Семеняка, Д. В. Атаманский // Современные информационные и электронные технологии : XIII междунар. научн.-практ. конф., 4-8 июня 2012, Одесса, Украина : тез.докл. - Одесса : ОНПУ, 2012. - С. 21.

4. Леховицкий Д. И. СДЦ в импульсных РЛС: с формулами и картинками. 2. Физический смысл и экстремальные свойства операций оптимальной междупериодной обработки гауссовых сигналов на фоне гауссовых пассивных помех / Д. И. Леховицкий, В. П. Рябуха, Г. А. Жуга // Прикладная радиоэлектроника. - 2008. - № 2. - C. 109-123.

5. S.L. Marple, Jr., Digital Spectral Analysis with Applications, Prentice Hall, 1987

6. Караваев В. В., Сазонов В. В. Статистическая теория пассивной локации. - М.: Радио и связь, 1987. - $240 \mathrm{c}$.

7. Яглом А.М. Корреляционная теория стационарных случайных функций с примерами из метеорологии. - Л. Гидрометеоиздат.-1991. 226 с.

8. Krim H. and Viberg M. Two Decades of Array Signal Processing Research // IEEE Signal Processing Magazine. - 1996. - № 7. — P. 67-95.

9. Stoica P. and Moses R. Introduction to Spectral Analysis. — NJ.: Prentice Hall, Upper Saddle River, 1997.

10. Баскаков С.И. Радиотехнические цепи и сигналы:Учебник / С.И. Баскаков. - М.: Высшая школа, 1983. - $536 \mathrm{c}$.

11. Capon J. High Resolution Frequency-Wave number Spectrum Analysis / J. Capon // Proc. IEEE. 1969. - Vol. 57, No. 8. - P. 1408-1418.

12. Кейпон Дж. Распределение вероятности оценок пространственно-временного спектра / Дж. Кейпон, Н. Гудмен // ТИИЭР. — 1970. - Т. 58, № 11. - С. $82-84$.

13. Гейбриел У. Ф. Спектральный анализ и методы сверхразрешения с использованием адаптивных антенных решеток / У.Ф. Гейбриел // ТИИЭР. — 1980. 一 Т. 68, № 6. - С. 19-32.

Поступила в редакцию 23.03.2016 